\title{
Implications of nipple discharge in Hong Kong Chinese women
}

\author{
WM Kan, Clement Chen, Ava Kwong *
}

\section{A B S T R A C T}

Introduction: There are no recent data on nipple discharge and its association with malignancy in Hong Kong Chinese women. This study reported our 5-year experience in the management of patients with nipple discharge, and our experience of mammography, ultrasonography, ductography, and nipple discharge cytology in an attempt to determine their role in the management of nipple discharge.

Methods: Women who attended our Breast Clinic in a university-affiliated hospital in Hong Kong were identified by retrospective review of clinical data from January 2007 to December 2011. They were divided into benign and malignant subgroups. Background clinical variables and investigative results were compared between the two subgroups. We also reported the sensitivity, specificity, and positive and negative predictive values of the investigations that included mammography, ultrasonography, ductography, and cytology.

Results: We identified 71 and 31 patients in the benign and malignant subgroups, respectively. The median age at presentation for the benign subgroup was younger than that of the malignant subgroup (48 vs 59 years; $\mathrm{P}=0.003$ ). A higher proportion of patients in the malignant subgroup than the benign subgroup presented with bloodstained nipple discharge ( $87.1 \%$ vs $47.9 \% ; \mathrm{P}=0.002)$. positive predictive value of $66.7 \%$; ultrasonography had a specificity of $87.0 \%$ and negative predictive value of $75.0 \%$. Cytology and ductography were sensitive but lacked specificity. Ductography had a negative predictive value of $100 \%$ but a low positive predictive value (14.0\%). Clinical variables including age at presentation, duration of discharge, colour of discharge, presence of an associated breast mass, and abnormal sonographic findings were important in suggesting the underlying pathology of nipple discharge. Multiple logistic regression showed that blood-stained discharge and an associated breast mass were statistically significantly more common in the malignant subgroup.

Conclusions: In patients with non-bloodstained nipple discharge, a negative clinical breast examination combined with negative imaging could reasonably infer a benign underlying pathology.

\section{Hong Kong Med J 2018;24:18-24 \\ DOI: $10.12809 / \mathrm{hkmj} 154764$}

${ }^{1}$ WM Kan, FCSHK, FHKAM (Surgery)

${ }^{2} \mathrm{C}$ Chen, FRCS, FHKAM (Surgery)

${ }^{2}$ A Kwong *, FRCS, FHKAM (Surgery)

Department of Surgery, Queen Elizabeth Hospital, Jordan, Hong Kong

2 Department of Surgery, Queen Mary Hospital, Pokfulam, Hong Kong Mammography had a specificity of $98.4 \%$ and * Corresponding author: avakwong@hku.hk

New knowledge added by this study

Blood-stained nipple discharge and an associated breast mass at presentation could suggest a higher chance of malignancy.

Implications for clinical practice or policy

- A period of watchful waiting is a reasonable alternative to surgical intervention in patients with inferred benign pathology.

\section{Introduction}

Nipple discharge is a relatively uncommon complaint in Hong Kong Chinese women. According to a study in 1997, nipple discharge constituted $1.5 \%$ of all presenting complaints for women who attended a breast clinic in Hong Kong. ${ }^{1}$ On the contrary, nipple discharge accounted for up to $4 \%$ to $7 \%$ of all presenting symptoms in other studies., ${ }^{2,3}$ This may be better explained by the unique Chinese culture and help-seeking pattern rather than a true disease pattern. With this understanding, any clinical survey will probably underestimate the prevalence of nipple discharge in Chinese women. When patients approach health care professionals because of nipple discharge, not only is it important to differentiate malignant from benign causes of nipple discharge, it is also a valuable opportunity to promote breast health awareness.

Numerous studies have demonstrated the relationship between breast cancer and nipple discharge, with malignancy reported in up to $9.3 \%$ to $21 \%$ of all patients who present with nipple 
discharge. ${ }^{4,5}$ The most challenging role of breast surgeons is to accurately identify these patients. Notwithstanding, controversy persists about the value and accuracy of individual investigative tools for nipple discharge. ${ }^{6}$

There are no recent data on nipple discharge and its association with malignancy in Chinese women in Hong Kong. The primary aim of this study was to report our recent experience in the management of patients with nipple discharge in a single surgical centre. The secondary aim was to report our experience of individual investigative tools in an attempt to determine their role in the management of nipple discharge.

\section{Methods}

We retrospectively reviewed the clinical data of patients who attended our Breast Clinic at the Queen Mary Hospital, a university-affiliated hospital in Hong Kong, for nipple discharge from January 2007 to December 2011. Potential subjects were identified when diagnosis coding 611.79 (other signs and symptoms in breast) was entered into our Clinical Management System, which is a territorywide computer-based medical record system designed for use in public hospitals, and also from the prospective database of the Division of Breast Surgery, The University of Hong Kong.

Data extraction and coding were performed by the first author (WM Kan) and included duration of follow-up until December 2011, age at presentation, history of breast condition, and laterality and duration of nipple discharge before first consultation. Clinical variables included colour of nipple discharge, singleor multiple-duct discharge, associated symptoms, mammographic and ultrasonographic imaging results, as well as ductogram and cytology results. Pathology results were recorded for patients who underwent surgery or biopsy.

In order to make a meaningful comparison, we divided patients into malignant and benign subgroups. The malignant subgroup was defined by malignant pathology on a surgically resected specimen. The benign subgroup was defined by benign pathology of a surgically resected or biopsy specimen, or clinical non-progression after more than 2 years of follow-up. Patients who did not undergo surgery or biopsy and who were followed up for less than 2 years were excluded (Fig).

In the first part of our study, we compared the background clinical variables and investigative results between the two subgroups. In the second part of our analysis, we reported the sensitivity, specificity, positive predictive value, and negative predictive value of individual investigative tools.

For the purpose of this analysis, we also classified the results of clinical examination, mammography, ultrasonography, and cytology as 'test positive' or

\section{香港華籍女性乳頭溢液的預示

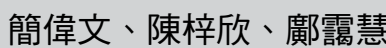

引言 : 近代文獻中未有關於香港華籍女性乳頭溢液以及其相關惡性腫 瘤的資料。本研究報告我們 5 年來處理有關乳頭溢液病例的經驗, 並 回顧乳房X光造影、超聲檢查、乳管造影和乳頭溢液細胞學檢查的病 例, 從而確定這些檢測在乳頭溢液治療過程中的角色。

方法：回顧分析2007年1月至2011年12月期間，所有到香港一所大學 教學醫院的乳房護理診所求診的病人的臨床資料。我們把病人分為良 性和惡性腫瘤兩組, 然後比較兩組的背景臨床資料和檢查結果, 並報 告乳房X光造影、超聲檢查、細胞學和乳管造影檢查的敏感性、特異 性，以及其陽性和陰性預測值。

結果：良性和惡性腫瘤兩組分別有 71 例和 31 例。良性腫瘤組別的病 人年齡中位數顯著低於惡性腫瘤組別（48歲比59歲； $\mathrm{P}=0.003 ）$ 惡性腫瘤組別中有較多患者的乳頭有血性溢液（ $87.1 \%$ 比 $47.9 \%$; $\mathrm{P}=0.002$ ）。乳房X光造影的特異性 $98.4 \%$ ，陽性預測值 $66.7 \%$; 超聲 檢查的特異性 $87.0 \%$, 陰性預測值 $75.0 \%$ 。細胞學和乳管造影檢查的敏 感度高, 可惜缺乏特異性。乳管造影檢查的陰性預測值有 $100 \%$, 但其 陽性預測值偏低（14.0\%）。患者年齡、溢液持續期、溢液顏色、是 否有相關的乳房腫塊和異常的超聲檢查結果, 對於反映乳頭溢液的潛 在病理狀況相當重要。多元邏輯迴歸分析顯示惡性腫瘤組別中, 患者 的乳頭有血性溢液和相關乳腺腫塊的情況明顯較多。

結論：對於無出現乳頭血性溢液的患者, 如果其臨床乳腺檢查和造影 顯像均為陰性時, 便可合理地推斷患者屬良性腫瘤的病例。

'test negative' for underlying malignancy. Presence of a palpable breast mass (regardless of mobility) was considered a positive result and no palpable breast mass a negative result. For mammographic findings, microcalcifications were considered a positive result. For ultrasonography, a detectable mass was 'test positive' for underlying malignancy; non-solitary dilated ducts, cysts, and normal ultrasonogram were regarded as 'test negative'. For ductogram results, dilated ducts, irregularity, and the presence of ductal filling defects were considered positive. For cytology, atypical, suspicious, and malignant were considered 'test positive', and benign as 'test negative.' This study was done in accordance with the principles outlined in the Declaration of Helsinki.

\section{Statistical analysis}

$\mathrm{R}$ version 3.0.2 (the $\mathrm{R}$ Foundation) and the SPSS (Windows version 14.0; SPSS Inc, Chicago [IL], United States) were used for data analysis. To determine the differences between subgroups, Wilcoxon rank sum test and Fisher's exact test were used for numerical data and categorical data, respectively. Multiple logistic regression was performed to examine the odds ratios of the factors. Backward selection through likelihood ratio test with removal of $\mathrm{P}$ value of 0.1 was conducted for model selection. Variables in univariate analysis with 


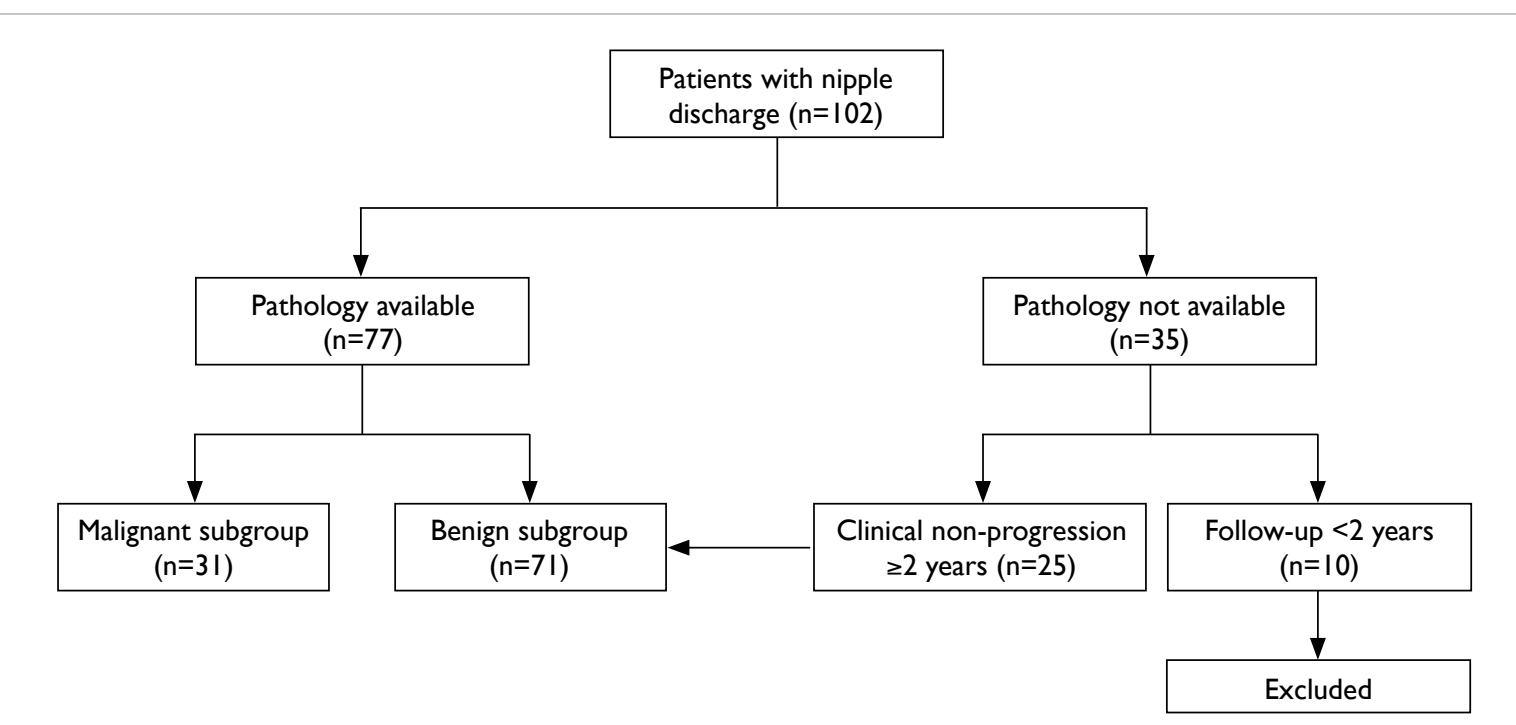

FIG. Algorithm for patient selection

a P value of $<0.1$ were included in the full model. A P value of $<0.05$ was considered statistically significant.

\section{Results}

Table 1 summarises the first part of our analysis. We identified 102 patients who presented to our Breast Clinic during the study period. They had either a tissue diagnosis or had been followed up for longer than 2 years without tissue diagnosis. There were 31 and 71 patients in the malignant and benign subgroups, respectively.

The median age at presentation of the benign subgroup was significantly younger than that of the malignant subgroup ( 48 vs 59 years; $\mathrm{P}=0.003$ ). The median interval between onset of nipple discharge and first presentation was significantly longer in the benign subgroup than in the malignant subgroup (13 vs 4 weeks; $\mathrm{P}=0.002$ ).

Comparing the two subgroups, a larger proportion of patients in the malignant subgroup presented with blood-stained discharge $(87.1 \%$ vs 47.9\%; $\mathrm{P}=0.002$ ) and had a breast mass at presentation $(46.7 \%$ vs $7.0 \% ; \mathrm{P}<0.001)$. For the individual investigative modalities, with the exception of ultrasonography, neither mammography, ductography nor cytology showed any statistically significant difference between the malignant and benign subgroups.

Table 2 summarises the second part of the study. We calculated the sensitivity, specificity, and positive and negative predictive values of mammographic, ultrasonographic, cytological, and ductographic findings. There were $83,95,27$, and 46 patients who underwent mammography, ultrasonography, cytology, and ductography, respectively. The positive and negative predictive values of cytology were $41.2 \%$ and $80.0 \%$, respectively. Ductography had a sensitivity of $100 \%$, specificity of $7.5 \%$, positive predictive value of $14.0 \%$, and negative predictive value of $100 \%$.

Multiple logistic regression analysis with backward selection was performed. Covariates with a $\mathrm{P}$ value of $<0.1$ were included in the full model (Table 1). By likelihood ratio test and removal of variables with a $P$ value of $>0.1$, duration of nipple discharge, colour of nipple discharge, mastalgia, and associated mass remained in the final model (Table $3)$.

Compared with serous, milky and brownish discharge, patients with blood-stained discharge had a significantly higher risk for malignancy (odds ratio $=13.368 ; 95 \%$ confidence interval, 1.926-92.809). In addition, compared with patients having no symptoms, those with a breast mass had a significantly higher risk for malignancy (odds ratio $=14.648$; 95\% confidence interval, 3.155-68.000) [Table 3].

\section{Discussion}

A methodologically ideal study of nipple discharge would require every patient to undergo the same investigations and also surgery for final pathology. This, however, would be unethical. For patients who opted for non-operative management of nipple discharge, our retrospective study considered 2-year clinical non-progression a reasonable surrogate for benign breast pathology.

\section{Clinical variables}

Women in the malignant subgroup were significantly 
TABLE I. Bivariate analysis of tumour type (benign or malignant) and other clinical variables

\begin{tabular}{|c|c|c|c|}
\hline \multirow[t]{2}{*}{ Variable* } & \multicolumn{2}{|c|}{ Median (range) or No. (\%) of patients } & \multirow{2}{*}{$\begin{array}{l}\text { P value (Fisher's exact/ } \\
\text { Wilcoxon rank sum test) }\end{array}$} \\
\hline & Malignant (n=31) & Benign $(n=71)$ & \\
\hline Duration of follow-up (weeks) & $129(9-261)$ & $173(7-266)$ & 0.190 \\
\hline Age at presentation (years) & $59(36-91)$ & $48(24-87)$ & 0.003 \\
\hline History of malignancy in contralateral breast & $1(3.2)$ & $3(4.2)$ & 1 \\
\hline Laterality of nipple discharge (unilateral / bilateral) & $29(93.5) / 2(6.5)$ & $56(78.9) / 15(21.1)$ & 0.085 \\
\hline Duration of nipple discharge before consultation (weeks) & $4(1-26)$ & $13(1-520)$ & 0.002 \\
\hline \multicolumn{4}{|l|}{ Colour of nipple discharge } \\
\hline Serous & $3(9.7)$ & $22(31.0)$ & 0.002 \\
\hline Milky & $1(3.2)$ & $8(11.3)$ & \\
\hline Brownish & 0 & $7(9.9)$ & \\
\hline Blood-stained & $27(87.1)$ & $34(47.9)$ & \\
\hline \multicolumn{4}{|l|}{ Single / multiple duct $(n=82)$} \\
\hline Single duct & $10(71.4)$ & $59(86.8)$ & 0.222 \\
\hline Multiple duct & $4(28.6)$ & $9(13.2)$ & \\
\hline \multicolumn{4}{|l|}{ Associated symptoms $(n=101)$} \\
\hline No symptoms & $14(46.7)$ & $58(81.7)$ & $<0.001$ \\
\hline Mastalgia & $2(6.7)$ & $8(11.3)$ & \\
\hline Breast mass & $14(46.7)$ & $5(7.0)$ & \\
\hline \multicolumn{4}{|l|}{ Mammogram (n=83) } \\
\hline Microcalcifications & $2(9.5)$ & $1(1.6)$ & 0.156 \\
\hline Normal & $19(90.5)$ & $61(98.4)$ & \\
\hline \multicolumn{4}{|l|}{ Ultrasonogram (n=95) } \\
\hline Normal & $4(15.4)$ & $34(49.3)$ & $<0.001$ \\
\hline Cyst & $11(42.3)$ & $5(7.2)$ & \\
\hline Dilated ducts & $5(19.2)$ & $21(30.4)$ & \\
\hline Mass & $6(23.1)$ & $9(13.0)$ & \\
\hline \multicolumn{4}{|l|}{ Ductogram $(n=46)$} \\
\hline Normal & 0 & $3(7.5)$ & 0.900 \\
\hline Dilated ducts & $2(33.3)$ & $9(22.5)$ & \\
\hline Irregularity & $1(16.7)$ & $7(17.5)$ & \\
\hline Filing defect & $3(50.0)$ & $21(52.5)$ & \\
\hline \multicolumn{4}{|l|}{ Cytology (n=27) } \\
\hline Benign & $2(22.2)$ & $8(44.4)$ & 0.383 \\
\hline Atypical & $5(55.6)$ & $8(44.4)$ & \\
\hline Suspicious & $2(22.2)$ & $1(5.6)$ & \\
\hline Malignant & 0 & $1(5.6)$ & \\
\hline
\end{tabular}

* Data were missing for some patients

TABLE 2. Sensitivity, specificity, and positive/negative predictive values of different modalities

\begin{tabular}{lcccc}
\hline & $\begin{array}{c}\text { Mammography } \\
\text { (microcalcifications with } \\
\text { or without a mass) [n=83] }\end{array}$ & $\begin{array}{c}\text { Ultrasonography (mass) } \\
\text { [n=95] }\end{array}$ & $\begin{array}{c}\text { Cytology (atypical, } \\
\text { suspicious, and } \\
\text { malignant) [n=27] }\end{array}$ & $\begin{array}{c}\text { Ductography (dilated } \\
\text { ducts, irregularity, and } \\
\text { filling defect) [n=46] }\end{array}$ \\
\hline Sensitivity & $9.5 \%$ & $23.1 \%$ & $77.8 \%$ & $100 \%$ \\
Specificity & $98.4 \%$ & $87.0 \%$ & $44.4 \%$ & $7.5 \%$ \\
Positive predictive value & $66.7 \%$ & $40.0 \%$ & $41.2 \%$ & $14.0 \%$ \\
Negative predictive value & $76.3 \%$ & $75.0 \%$ & $80.0 \%$ & $100 \%$ \\
\hline
\end{tabular}


TABLE 3. Multiple logistic regression of factors associated with malignancy

\begin{tabular}{|c|c|c|c|}
\hline & Odds ratio & $95 \%$ Confidence interval & $P$ value \\
\hline Duration of nipple discharge before consultation & 0.969 & $0.920-1.020$ & 0.227 \\
\hline \multicolumn{4}{|c|}{ Colour of nipple discharge (ref: serous / milky / brownish) } \\
\hline Blood-stained & 13.368 & $1.926-92.809$ & 0.009 \\
\hline \multicolumn{4}{|l|}{ Associated symptoms (ref: no symptoms) } \\
\hline Mastalgia & 8.004 & $0.698-91.741$ & 0.095 \\
\hline Breast mass & 14.648 & $3.155-68.000$ & $<0.001$ \\
\hline
\end{tabular}

older at presentation than their benign counterparts. This was in agreement with the fact that physiological nipple discharge is more common in younger premenopausal women. Caution should be exercised in postmenopausal women who present with nipple discharge and the possibility of malignancy investigated before concluding a benign pathology.

With respect to the colour of nipple discharge, underlying benign and malignant causes had a different pattern. Benign pathology was more likely to be associated with non-blood-stained discharge $(\mathrm{n}=37,52.1 \%)$, whereas malignant pathology was more likely to be associated with blood-stained discharge $(n=27,87.1 \%)$. This is not pathognomonic but did reach statistical significance.

The differentiation between multiple-duct and single-duct discharge showed no association with underlying pathology.

\section{Mammography and ultrasonography}

As shown in Table 2, mammography had a higher specificity of $98.4 \%$ and positive predictive value of $66.7 \%$ but a disappointingly low sensitivity of $9.5 \%$. Therefore, a normal mammogram did not confidently exclude malignancy. On the other hand, breast ultrasonography had a specificity and negative predictive value of $87.0 \%$ and $75.0 \%$, respectively. Mammography was routinely offered to patients who presented with nipple discharge. Complementary breast ultrasonography was also arranged, especially for younger Asian women with denser breasts on mammography. ${ }^{7}$ In our experience, complementary ultrasonography increases the overall sensitivity and negative predictive value compared with mammography alone.

\section{Nipple discharge cytology}

Opinion is divided on the value of cytological examination. While some studies report a complementary diagnostic value and recommend its routine use, ${ }^{8,9}$ others report it has little such value and advise against its routine use. ${ }^{10}$

Of the 102 patients, 36 had demonstrable nipple discharge at consultation with a sample collected for examination. Of these 36 specimens, only 27 showed a sufficient number of cells to make a cytological diagnosis. Nonetheless, we attempted to analyse its accuracy. The sensitivity and specificity of cytological examination were $77.8 \%$ and $44.4 \%$, respectively. Its positive predictive value was disappointingly low at $41.2 \%$ and its negative predictive value was $80.0 \%$. The diagnostic value of this investigation was limited as not every patient had demonstrable nipple discharge and not every specimen contained adequate cells for testing. Nonetheless, this investigation is minimally invasive so was always performed if there was demonstrable nipple discharge, although it rarely affected the clinical decision or plan of management.

\section{Ductography}

The value of ductography is debatable. While some studies have validated the diagnostic value of preoperative ductography in differentiating benign and malignant pathology, ${ }^{11,12}$ others doubt its value. ${ }^{13}$ Rather than differentiating benign and malignant pathology, we used preoperative ductogram to aid in the localisation of non-palpable lesions. ${ }^{14,15}$ The sensitivity was $100 \%$ whereas the specificity was low at $7.5 \%$, with a positive predictive value of $14.0 \%$ and a negative predictive value of $100 \%$.

\section{Magnetic resonance imaging}

Magnetic resonance imaging was not included in our routine evaluation of patients with nipple discharge although we acknowledge its value in the detection of carcinoma in these patients. It has an exceptionally high sensitivity for both invasive and in-situ carcinoma. ${ }^{16}$ Its routine use in patients with a breast lesion is nonetheless limited by its relatively low specificity of $72 \%$ (95\% confidence interval, $67 \%$ $77 \%) .{ }^{17}$ The role of magnetic resonance imaging in patients with nipple discharge has been extensively validated ${ }^{18-21}$ suggesting that it may detect or exclude the presence of carcinoma with a high degree of certainty. Magnetic resonance imaging may be considered when all other available strategies are inconclusive. 


\section{Microdochectomy}

Emerging evidence suggests that neither clinical variables nor preoperative investigations reliably distinguish benign and malignant pathology so duct excision should be offered to every patient with nipple discharge. ${ }^{22-26} \mathrm{We}$ offered microdochectomy to patients with no palpable breast lesion based on two indications: clinical or radiological suspicion, or a patient's wish to stop nipple discharge by surgery. It is likely that offering microdochectomy to all patients with nipple discharge would result in overtreatment, as the final pathology was benign in most cases. In patients with negative clinical examination and negative imaging findings, a period of watchful waiting with regular follow-up is a reasonable alternative to surgical intervention.

The association of blood-stained discharge with malignancy is controversial. Morrogh et $\mathrm{al}^{24}$ reported that haemorrhagic discharge did not indicate malignancy or high risk, and nonhaemorrhagic discharge did not exclude malignancy. In our study, we showed that blood-stained discharge was associated with malignancy but was not pathognomonic.

On the other hand, presence of an associated breast mass was a significant finding. This may be because it is the most common presenting symptom of breast cancer, and its incidence rises with age.

\section{Limitations}

Our study had several limitations. First, as data collection was retrospective, there might have been inconsistent or incomplete recording of clinical findings. Study subjects might not be representative and some data for importable variables might have been missing. No blinding during information extraction or coding could be achieved as it was performed by the first author. Second, the small sample size limited the power of our study although this could in part be due to the relatively conservative culture and help-seeking pattern of Hong Kong Chinese women. The unequal arm size also limited the interpretation of statistical significance of comparisons. Third, our assumption of 2-year clinical non-progression as benign pathology might have underestimated the true incidence of malignancy in our group of patients. Lastly, the small number of adequate cytology specimens limited meaningful analysis of this investigation. As the sample taken for cytology is usually small, it will affect the sensitivity.

\section{Conclusions}

Clinical variables including age at presentation, duration and colour of discharge, presence of an associated breast mass, and abnormal sonographic findings were important in suggesting the underlying pathology of nipple discharge. Only blood-stained nipple discharge and an associated breast mass remained in the multiple logistic regression model and were statistically significant. In patients with nonblood-stained nipple discharge, as well as a negative clinical breast examination and imaging, we may infer an underlying benign pathology. Further prospective studies with a larger sample size are advocated.

\section{Declaration}

All authors have disclosed no conflicts of interest.

\section{Acknowledgements}

The authors would like to thank Mr Wing-pan Luk and Mr Ling-hiu Fung, Medical Physics \& Research Department, Hong Kong Sanatorium \& Hospital, Hong Kong for their statistical contribution to this paper.

\section{References}

1. Cheung KL, Alagaratnam TT. A review of nipple discharge in Chinese women. J R Coll Surg Edinb 1997;42:179-81.

2. Murphy IG, Dillon MF, Doherty AO, et al. Analysis of patients with false negative mammography and symptomatic breast carcinoma. J Surg Oncol 2007;96:457-63.

3. Vargas HI, Vargas MP, Eldrageely K, Gonzalez KD, Khalkhali I. Outcomes of clinical and surgical assessment of women with pathological nipple discharge. Am Surg 2006;72:124-8.

4. Murad TM, Contesso G, Mouriesse H. Nipple discharge from the breast. Ann Surg 1982;195:259-64.

5. King TA, Carter KM, Bolton JS, Fuhrman GM. A simple approach to nipple discharge. Am Surg 2000;66:960-6.

6. Jain A, Crawford S, Larkin A, Quinlan R, Rahman RL. Management of nipple discharge: technology chasing application. Breast J 2010;16:451-2.

7. Kwong A, Cheung PS, Wong AY, et al. The acceptance and feasibility of breast cancer screening in the East. Breast 2008;17:42-50.

8. Pritt B, Pang Y, Kellogg M, St. John T, Elhosseiny A. Diagnostic value of nipple cytology: study of 466 cases. Cancer 2004;102:233-8.

9. Kalu ON, Chow C, Wheeler A, Kong C, Wapnir I. The diagnostic value of nipple discharge cytology: breast imaging complements predictive value of nipple discharge cytology. J Surg Oncol 2012;106:381-5.

10. Kooistra BW, Wauters C, van de Ven S, Strobbe L. The diagnostic value of nipple discharge cytology in 618 consecutive patients. Eur J Surg Oncol 2009;35:573-7.

11. Hou MF, Huang TJ, Liu GC. The diagnostic value of galactography in patients with nipple discharge. Clin Imaging 2001;25:75-81.

12. Hou MF, Huang CJ, Huang YS, et al. Evaluation of galactography for nipple discharge. Clin Imaging 1998;22:89-94.

13. Dawes LG, Bowen C, Venta LA, Morrow M. Ductography for nipple discharge: no replacement for ductal excision. Surgery 1998;124:685-91.

14. Peters J, Thalhammer A, Jacobi V, Vogl TJ. Galactography: an important and highly effective procedure. Eur Radiol 2003;13:1744-7. 
15. Lamont JP, Dultz RP, Kuhn JA, Grant MD, Jones RC. Galactography in patients with nipple discharge. Proc (Bayl Univ Med Cent) 2000;13:214-6.

16. Heywang-Koebrunner SH. Diagnosis of breast cancer with MR-review after 1250 patients. Electromedica 1993;61:43-52.

17. Peters NH, Borel Rinkes IH, Zuithoff NP, Mali WP, Moons KG, Peeters PH. Meta-analysis of MR imaging in the diagnosis of breast lesions. Radiology 2008;246:116-24.

18. Orel SG, Dougherty CS, Reynolds C, Czerniecki BJ Siegelman ES, Schnall MD. MR imaging in patients with nipple discharge: initial experience. Radiology 2000;216:248-54.

19. Nakahara H, Namba K, Watanabe R, et al. A comparison of MR imaging, galactography and ultrasonography in patients with nipple discharge. Breast Cancer 2003;10:320-

20. Hirose M, Otsuki N, Hayano D, et al. Multi-volume fusion imaging of MR ductography and MR mammography for patients with nipple discharge. Magn Reson Med Sci 2006;5:105-12.

21. Ballesio L, Maggi C, Savelli S, et al. Role of breast magnetic resonance imaging (MRI) in patients with unilateral nipple discharge: preliminary study [in English, Italian]. Radiol Med 2008;113:249-64.

22. Adepoju LJ, Chun J, El-Tamer M, Ditkoff BA, Schnabel F, Joseph KA. The value of clinical characteristics and breastimaging studies in predicting a histopathologic diagnosis of cancer or high-risk lesion in patients with spontaneous nipple discharge. Am J Surg 2005;190:644-6.

23. Lanitis S, Filippakis G, Thomas J, Christofides T, Al Mufti R, Hadjiminas DJ. Microdochectomy for single-duct pathologic nipple discharge and normal or benign imaging and cytology. Breast 2008;17:309-13.

24. Morrogh M, Park A, Elkin EB, King TA. Lessons learned from 416 cases of nipple discharge of the breast. Am J Surg 2010;200:73-80.

25. Alcock C, Layer GT. Predicting occult malignancy in nipple discharge. ANZ J Surg 2010;80:646-9.

26. Foulkes RE, Heard G, Boyce T, Skyrme R, Holland PA, Gateley CA. Duct excision is still necessary to rule out breast cancer in patients presenting with spontaneous bloodstained nipple discharge. Int J Breast Cancer 2011;2011:495315. 